\title{
Nonlinear Coupled Dynamic Modelling of Driver-seat-cab System and Biomechanical Behaviour Prediction
}

\author{
Leilei Zhao ${ }^{1}$ - Yuewei Yul, ${ }^{1}$ - Jianhu Cao ${ }^{1}$ - Weiwei Zhou ${ }^{2}$ \\ ${ }^{1}$ Shandong University of Technology, School of Transportation and Vehicle Engineering, China \\ 2 Zibo Vocational Institute, School of Automotive Engineering, China
}

The biomechanical responses of the driver-truck system in a dynamic environment have become a significant concern in the design and control of trucks. When evaluating the riding comfort of the seat-cab system, it is necessary to predict the biomechanical responses of the driver's different parts and directions. However, there is no reliable model and method for effectively predicting the response characteristics of the driver-seat-cab system. Aiming at such problem, firstly, based on the 7 DOF (degree-of-freedom) seated human biodynamic model established previously, a 10 DOF non-linear dynamic model of the driver-seat-cab system was created, and its vibration differential equations were established. Secondly, the vibration signals for simulation and verification were collected through the road test using a truck. Thirdly, based on the Newmark- $\beta$ integration method, the specific solution process of the model was given. The non-linear damping coefficients of the front and rear dampers for the cab suspensions were measured with a bench test. Moreover, the simulations were conducted based on the measured model parameters, taking the collected frame vibration signals as the inputs. The results show that the simulation results agree with the test results, proving that the dynamic model can effectively predict the driver's biomechanical responses. Finally, some useful conclusions were obtained through the simulation analysis. The established model and conclusions can provide technical support for comfort evaluation, optimization design, and control of the seat-cab suspension system.

Keywords: driver-seat-cab system, driver's health, dynamic modelling, biomechanical responses

Highlights

- A 10 DOF non-linear dynamic model of the driver-seat-cab system was created.

- $\quad$ The proposed dynamic model can effectively predict the driver's biomechanical responses.

- $\quad$ The driver's vertical vibration caused by the road excitation mainly concentrates in $0 \mathrm{~Hz}$ to $10 \mathrm{~Hz}$.

\section{INTRODUCTION}

When trucks run on real roads, the vibration caused by road roughness directly affects ride comfort and human health [1]. When the vibration reaches a certain level, it will make drivers feel uncomfortable, even cause traffic accidents [2]. Thus, it is imperative to study the vibration characteristics of the drivervehicle under the dynamic environment. Moreover, it has significant application values in truck design, dynamic simulation, the auxiliary analysis of the manmachine interface, and the prediction of the driver's biomechanical responses [3].

With the rapid development of the truck industry, improving ride comfort has become a significant concern of modern truck designers [4] and [5]. The seat-cab system is an essential part of modern trucks [6] and [7]. Their suspension systems directly affect the NVH (noise, vibration, and harshness) performance [8] and [9]. The optimal design of the seat-cab system through dynamic models is an important and effective means to improve ride comfort. It is the premise and basis to accurately simulate the biomechanical responses of the driver coupled with the seat-cab system for the design and optimization of the cab and/or seat suspension [10]. If the biomechanical responses obtained are inaccurate, it is easy to lead to wrong optimization results.

The research methods of the vibration of driver-vehicle systems can be roughly divided into two categories: the experimental method and the theoretical method [11]. In recent years, with the development of testing technology, the experimental method has been widely applied. However, because of the restriction of the high cost of the test conditions, the researchers have been seeking to theoretically simulate and predict the driver's biomechanical responses [12].

The truck driver's vibration can be divided into local vibration and whole-body vibration. The local vibration refers to the vibration of the driver's particular parts (e.g., the head and limbs), including the vibration of the driver's hand or feet. The wholebody vibration refers to the vibration transmitted to the body through the driver's supporting surface. The driver's vibration mainly belongs to the wholebody vibration, which is often transmitted to drivers through their buttocks and back [13]. Generally, the whole-body vibration is the primary vibration form that causes bodily harm to drivers. In order to evaluate 
the effects of the whole-body vibration on people, the International Standard Organization (ISO) proposed the international standard ISO 2631 [14], which has been supplemented and revised many times.

When studying the vibration of the driver-seatcab system for trucks, the driver is usually regarded as a rigid mass [15]. Marcu [16] studied the cab suspension control using a simplified cab model with 3 DOFs; however, he did not consider the driver-seatcab dynamics interaction. Akçay and Türkay [17] derived a 3 DOF (degree-of-freedom) cabin model to investigate the ride comfort of the cabin system for a truck; they regarded the driver-seat-cab as a rigid mass. Wang et al. [18] made a fatigue failure assessment based on loading reproduction for commercial vehicle cab. They also ignored the vibration characteristics of the driver-seat system. Liu et al. [19] optimized the ride comfort of cab mounts but did not consider the drivers' biomechanical characteristics. Zhao et al. [20] simulated the non-linear vibration responses of the cab system subject to suspension damper complete failure and took the driver-seat-cab as a rigid mass. These studies provide useful references for analysing the vibration of the driver-seat-cab system. However, few studies on integrated modelling and biomechanical responses simulation of the driver coupled with a seat-cab system for trucks undergoing random roads excitation exist.

The present paper's main objective is to provide a reliable model for effectively predicting the responses characteristics of the driver-seat-cab system. The previous work [21] proposed a 7 DOF seated human biodynamic model. The test results show that the biodynamic model can effectively reproduce the seated human biodynamic responses. In this paper, as the extension of the previous work, a 10 DOF nonlinear dynamic model of the driver-seat-cab system was proposed to simulate, analyse, and predict the driver's biomechanical responses for trucks undergoing random roads.

In Section 1, combined with the 7 DOF seated human biodynamic model, a 10 DOF non-linear dynamic model of the driver-seat-cab system was created, and its vibration differential equations were established. In Section 2, the vibration signals for simulation and verification were collected. In Section 3, the specific solution process of the model was given. In Section 4, the non-linear damping coefficients of the front and rear dampers for the cab suspensions were measured. Moreover, based on the measured model parameters and the collected frame vibration signals, the model was validated. In Section 5, the biomechanical responses of the driver coupled with the seat-cab were simulated. In Section 6 , some useful conclusions were obtained through the simulation analysis.

\section{INTEGRATED MODELLING OF DRIVER COUPLED WITH SEAT-CAB}

\subsection{The 10 DOF Driver-seat-cab Model}

To simulate, analyse, and predict the driver's biomechanical responses for trucks undergoing random roads excitation, a non-linear dynamic model of the driver-seat-cab system is proposed, as shown in Fig. 1; the driver sub-model is shown in Fig. 2. This sub-model is based on the previous work [21]. The proposed model has 10 DOFs, with two DOFs for the cab $\left(z_{\mathrm{c}}\right.$ and $\left.\varphi\right)$, one DOF for the seat $\left(z_{\mathrm{s}}\right)$, and seven DOFs for the driver $\left(z_{1}, z_{2}, z_{3}, z_{4}, z_{5}, x_{\mathrm{b}}\right.$, and $\left.\theta\right)$.

In Fig. 1, variables $a$ and $b$ are the horizontal distances from the front and rear suspensions to the cab mass centre, respectively; $h$ is the vertical distance between the mass centres of the driver and the cab; $l_{x}$ is the horizontal distance between the seat mounting point to the cab mass centre; $K_{\mathrm{s}}$ and $C_{\mathrm{s}}$ are the vertical stiffness and the damping coefficient of the seat suspension, respectively. The cab suspension system includes the front spring-damper assembly and the rear spring-damper assembly. $K_{\mathrm{f}}$ and $C_{\mathrm{f}}$ are the vertical stiffness and the damping coefficient of the front spring-damper assembly, respectively. $K_{\mathrm{r}}$ and $C_{\mathrm{r}}$ are the vertical stiffness and the damping coefficient of the rear spring-damper assembly, respectively. $C_{\mathrm{f}}$ and $C_{\mathrm{r}}$ nonlinearly depend on the relative motion velocities of the front damper and the rear damper, respectively. $q_{\mathrm{f}}$ and $q_{\mathrm{r}}$ are the frame displacements at the mounting positions of the front spring-damper assembly and the rear spring-damper assembly, respectively.

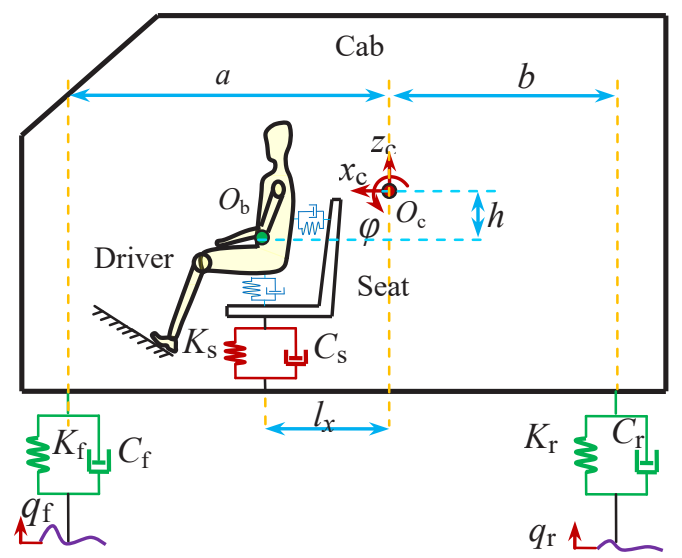

Fig. 1. The 10 DOF non-linear dynamic model of the driver-seat-cab system 


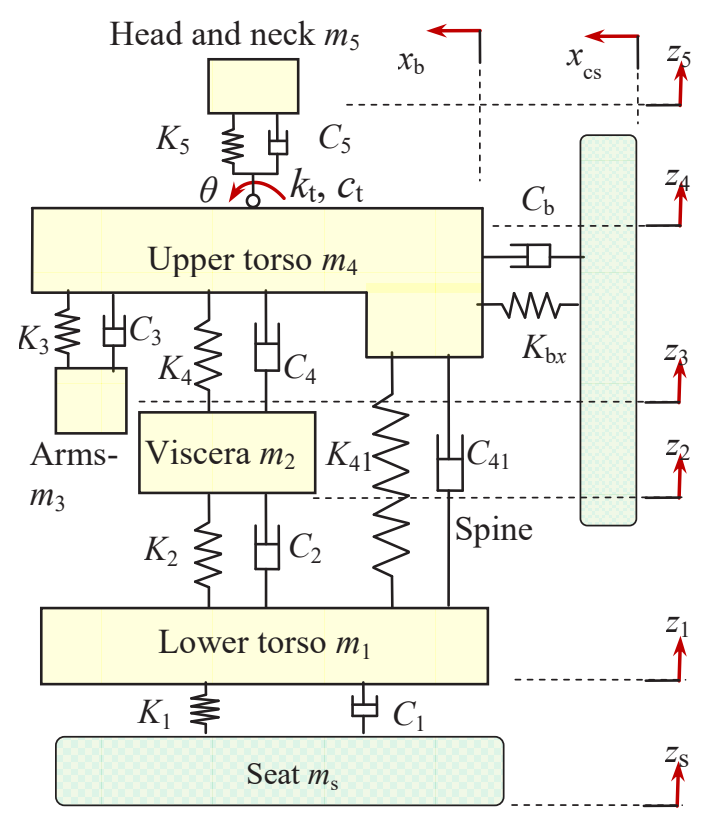

Fig. 2. The 7 DOF driver biodynamic model

In Fig. 2, the driver model is composed of two sub-models: the vertical model and the fore-andaft model [20]. The vertical model consists of five segments: head and neck, upper torso, arms, viscera, and lower torso. The spring $\left(K_{41}\right)$ and damper $\left(C_{41}\right)$ connecting the upper and lower torsos represent the body spine. In the fore-and-aft model, the main body mass $\left(m_{1}+m_{2}+m_{3}+m_{4}\right)$ is treated as a single combined mass. The head and neck and the main body are connected by a rotational degree. These rigid masses are coupled by linear elastic and damping elements.

\subsection{Non-linear Motion Equations}

\subsubsection{Differential Equations}

The differential equation of the cab vertical vibration can be expressed as

$$
\begin{aligned}
m_{\mathrm{c}} \ddot{z}_{\mathrm{c}} & =-K_{\mathrm{f}}\left(z_{\mathrm{c}}-a \varphi-q_{\mathrm{f}}\right)-C_{\mathrm{f}}\left(\dot{z}_{\mathrm{c}}-a \dot{\varphi}-\dot{q}_{\mathrm{f}}\right) \\
& -K_{\mathrm{r}}\left(z_{\mathrm{c}}+b \varphi-q_{\mathrm{r}}\right)-C_{\mathrm{r}}\left(\dot{z}_{\mathrm{c}}+b \dot{\varphi}-\dot{q}_{\mathrm{r}}\right) \\
& -\left[K_{\mathrm{s}}\left(z_{\mathrm{cs}}-z_{\mathrm{s}}\right)+C_{\mathrm{s}}\left(\dot{z}_{\mathrm{cs}}-\dot{z}_{\mathrm{s}}\right)\right],
\end{aligned}
$$

where, $C_{\mathrm{f}}$ and $C_{\mathrm{r}}$ can be further expressed as:

$$
\begin{aligned}
& C_{\mathrm{f}}=\left\{\begin{array}{ll}
C_{\mathrm{f}+} & \dot{z}_{\mathrm{c}}-a \dot{\varphi}-\dot{q}_{\mathrm{f}} \geq 0 \\
C_{\mathrm{f}-} & \dot{z}_{\mathrm{c}}-a \dot{\varphi}-\dot{q}_{\mathrm{f}}<0
\end{array},\right. \\
& C_{\mathrm{r}}=\left\{\begin{array}{ll}
C_{\mathrm{r}+} & \dot{z}_{\mathrm{c}}+b \dot{\varphi}-\dot{q}_{\mathrm{r}} \geq 0 \\
C_{\mathrm{r}-} & \dot{z}_{\mathrm{c}}+b \dot{\varphi}-\dot{q}_{\mathrm{r}}<0
\end{array} .\right.
\end{aligned}
$$

The differential equation of the cab pitch vibration can be expressed as

$$
\begin{aligned}
I \ddot{\varphi} & =\left[K_{\mathrm{f}}\left(z_{\mathrm{c}}-a \varphi-q_{\mathrm{f}}\right)+C_{\mathrm{f}}\left(\dot{z}_{\mathrm{c}}-a \dot{\varphi}-\dot{q}_{\mathrm{f}}\right)\right] a \\
& -\left[K_{\mathrm{r}}\left(z_{\mathrm{c}}+b \varphi-q_{\mathrm{r}}\right)+C_{\mathrm{r}}\left(\dot{z}_{\mathrm{c}}+b \dot{\varphi}-\dot{q}_{\mathrm{r}}\right)\right] b \\
& +\left[K_{\mathrm{s}}\left(z_{\mathrm{cs}}-z_{\mathrm{s}}\right)+C_{\mathrm{s}}\left(\dot{z}_{\mathrm{cs}}-\dot{z}_{\mathrm{s}}\right)\right] l_{x} \\
& +\left[K_{\mathrm{b}}\left(x_{\mathrm{cs}}-x_{\mathrm{b}}\right)+C_{\mathrm{b}}\left(\dot{x}_{\mathrm{cs}}-\dot{x}_{\mathrm{b}}\right)\right] h \\
& -k_{\mathrm{t}}(\varphi-\theta)-c_{\mathrm{t}}(\dot{\varphi}-\dot{\theta}),
\end{aligned}
$$

where, $I$ is the cab moment of inertia.

The differential equation of the seat vertical vibration can be expressed as

$$
\begin{aligned}
m_{\mathrm{s}} \ddot{z}_{\mathrm{s}} & =-K_{\mathrm{s}}\left(z_{\mathrm{s}}-z_{\mathrm{cs}}\right)-C_{\mathrm{s}}\left(\dot{z}_{\mathrm{s}}-\dot{z}_{\mathrm{cs}}\right) \\
& -K_{1}\left(z_{\mathrm{s}}-z_{1}\right)-C_{1}\left(\dot{z}_{\mathrm{s}}-\dot{z}_{1}\right) .
\end{aligned}
$$

The differential equation of the lower torso vertical vibration can be expressed as

$$
\begin{aligned}
m_{1} \ddot{z}_{1} & =-K_{1}\left(z_{1}-z_{\mathrm{s}}\right)-C_{1}\left(\dot{z}_{1}-\dot{z}_{\mathrm{s}}\right)-K_{2}\left(z_{1}-z_{2}\right) \\
& -C_{2}\left(\dot{z}_{1}-\dot{z}_{2}\right)-K_{41}\left(z_{1}-z_{4}\right)-C_{41}\left(\dot{z}_{1}-\dot{z}_{4}\right) .
\end{aligned}
$$

The differential equation of the viscera vertical vibration can be expressed as

$$
\begin{aligned}
m_{2} \ddot{z}_{2}= & -K_{2}\left(z_{2}-z_{1}\right)-C_{2}\left(\dot{z}_{2}-\dot{z}_{1}\right) \\
& -K_{4}\left(z_{2}-z_{4}\right)-C_{4}\left(\dot{z}_{2}-\dot{z}_{4}\right) .
\end{aligned}
$$

The differential equation of the arms vertical vibration can be expressed as

$$
m_{3} \ddot{z}_{3}=-K_{3}\left(z_{3}-z_{4}\right)-C_{3}\left(\dot{z}_{3}-\dot{z}_{4}\right) .
$$

The differential equation of the upper torso vertical vibration can be expressed as

$$
\begin{aligned}
m_{4} \ddot{z}_{4}= & -K_{3}\left(z_{4}-z_{3}\right)-C_{3}\left(\dot{z}_{4}-\dot{z}_{3}\right)-K_{4}\left(z_{4}-z_{2}\right) \\
& -C_{4}\left(\dot{z}_{4}-\dot{z}_{2}\right)-K_{41}\left(z_{4}-z_{1}\right)-C_{41}\left(\dot{z}_{4}-\dot{z}_{1}\right) \\
& -K_{5}\left(z_{4}-z_{5}\right)-C_{5}\left(\dot{z}_{4}-\dot{z}_{5}\right) .
\end{aligned}
$$

The differential equation of the head and neck vertical vibration can be expressed as

$$
m_{5} \ddot{z}_{5}=-K_{5}\left(z_{5}-z_{4}\right)-C_{5}\left(\dot{z}_{5}-\dot{z}_{4}\right) .
$$

The differential equation of the whole-body longitudinal vibration can be expressed as:

$$
\begin{gathered}
m_{\mathrm{b}} \ddot{x}_{\mathrm{b}}+m_{5} l_{n} \ddot{\theta} \cos \theta-m_{5} l_{n} \dot{\theta}^{2} \sin \theta= \\
=-K_{\mathrm{b}}\left(x_{\mathrm{b}}-x_{\mathrm{cs}}\right)-C_{\mathrm{b}}\left(\dot{x}_{\mathrm{b}}-\dot{x}_{\mathrm{cs}}\right),
\end{gathered}
$$

where, $m_{\mathrm{b}}=m_{1}+m_{2}+m_{3}+m_{4}$.

The differential equation of the head and neck pitch vibration can be expressed as

$$
\begin{aligned}
m_{5} l_{n}^{2} \ddot{\theta}+m_{5} l_{n} \ddot{x}_{\mathrm{b}} \cos \theta & =m_{5} l_{n} g \sin \theta-k_{\mathrm{t}}(\theta-\varphi) \\
& -c_{\mathrm{t}}(\dot{\theta}-\dot{\varphi}) .
\end{aligned}
$$


In addition, the cab vertical displacement $z_{\mathrm{cs}}$ at the seat installation position can be expressed as:

$$
z_{\mathrm{cs}}=z_{\mathrm{c}}-l_{x} \varphi .
$$

The longitudinal ( $x$-direction) displacement $x_{\mathrm{cs}}$ of the seat backrest can be expressed as:

$$
x_{\mathrm{cs}}=-h \varphi \text {. }
$$

\subsubsection{Matrix Equation}

The displacement, velocity, and acceleration response vectors of the proposed model can be expressed as

$$
\begin{aligned}
& \mathbf{u}=\left[z_{\mathrm{c}}, \varphi, z_{\mathrm{s}}, z_{1}, z_{2}, z_{3}, z_{4}, z_{5}, x_{\mathrm{b}}, \theta\right]^{\mathrm{T}}, \\
& \dot{\mathbf{u}}=\left[\dot{z}_{\mathrm{c}}, \dot{\varphi}, \dot{z}_{\mathrm{s}}, \dot{z}_{1}, \dot{z}_{2}, \dot{z}_{3}, \dot{z}_{4}, \dot{z}_{5}, \dot{x}_{\mathrm{b}}, \dot{\theta}\right]^{\mathrm{T}}, \\
& \ddot{\mathbf{u}}=\left[\ddot{z}_{\mathrm{c}}, \ddot{\varphi}, \ddot{z}_{\mathrm{s}}, \ddot{z}_{1}, \ddot{z}_{2}, \ddot{z}_{3}, \ddot{z}_{4}, \ddot{z}_{5}, \ddot{x}_{\mathrm{b}}, \ddot{\theta}\right]^{\mathrm{T}} .
\end{aligned}
$$

The displacement and velocity excitations of the proposed model can be expressed as

$$
\begin{aligned}
& \mathbf{q}=\left[q_{\mathrm{f}}, q_{\mathrm{r}}\right]^{\mathrm{T}}, \\
& \dot{\mathbf{q}}=\left[\dot{q}_{\mathrm{f}}, \dot{q}_{\mathrm{r}}\right]^{\mathrm{T}} .
\end{aligned}
$$

The matrix equation of the proposed model can be expressed as

$$
\mathbf{M} \ddot{\mathbf{u}}+\mathbf{C}_{u} \dot{\mathbf{u}}+\mathbf{K}_{u} \mathbf{u}=\mathbf{C}_{q} \dot{\mathbf{q}}+\mathbf{K}_{q} \mathbf{q},
$$

where, $\mathbf{M}$ is the mass matrix, $\mathbf{K}_{u}$ is the system stiffness matrix, $\mathbf{C}_{u}$ is the system damping matrix, $\mathbf{K}_{q}$ is the excitation stiffness matrix, $\mathbf{C}_{q}$ is the excitation damping matrix.

The matrix $\mathbf{C}_{u}$ can be expressed as

$$
\mathbf{C}_{u}=\left[\begin{array}{cccccccccc}
c_{11} & c_{12} & c_{13} & 0 & 0 & 0 & 0 & 0 & 0 & 0 \\
c_{21} & c_{22} & c_{23} & 0 & 0 & 0 & 0 & 0 & c_{29} & -c_{\mathrm{t}} \\
c_{31} & c_{32} & c_{33} & c_{34} & 0 & 0 & 0 & 0 & 0 & 0 \\
0 & 0 & c_{43} & c_{44} & c_{45} & 0 & c_{47} & 0 & 0 & 0 \\
0 & 0 & 0 & c_{54} & c_{55} & 0 & c_{57} & 0 & 0 & 0 \\
0 & 0 & 0 & 0 & 0 & c_{66} & c_{67} & 0 & 0 & 0 \\
0 & 0 & 0 & c_{74} & c_{75} & c_{76} & c_{77} & c_{78} & 0 & 0 \\
0 & 0 & 0 & 0 & 0 & 0 & c_{87} & c_{88} & 0 & 0 \\
0 & c_{92} & 0 & 0 & 0 & 0 & 0 & 0 & c_{99} & 0 \\
0 & -c_{\mathrm{t}} & 0 & 0 & 0 & 0 & 0 & 0 & 0 & c_{\mathrm{t}}
\end{array}\right],(21,
$$

where, $c_{11}=C_{\mathrm{f}}+C_{\mathrm{r}}+C_{\mathrm{s}}, c_{44}=C_{1}+C_{2}+C_{41}$, $c_{66}=C_{3}, c_{22}=a^{2} C_{\mathrm{f}}+b^{2} C_{\mathrm{r}}+l_{x}^{2} C_{\mathrm{s}}+h^{2} C_{\mathrm{b}}+c_{t}$, $c_{33}=C_{\mathrm{s}}+C_{1}, c_{55}=C_{4}+C_{2}, c_{77}=C_{3}+C_{4}+C_{41}+C_{5}$, $c_{88}=C_{5}, c_{99}=C_{\mathrm{b}}, c_{21}=c_{12}=a C_{\mathrm{f}}+b C_{\mathrm{r}}+l_{x} C_{\mathrm{s}}$, $c_{13}=c_{31}=-C_{\mathrm{s}}, c_{23}=c_{32}=l_{x} C_{\mathrm{s}}, c_{34}=c_{43}=-C_{1}$, $c_{45}=c_{54}=-C_{2}, c_{47}=c_{74}=-C_{41}, c_{57}=c_{75}=-C_{4}$, $c_{67}=c_{76}=-C_{3}, c_{78}=c_{87}=-C_{5}, c_{29}=c_{92}=h C_{\mathrm{b}}$.
The matrix $\mathbf{C}_{q}$ can be expressed as

$$
\mathbf{C}_{q}=\left[\begin{array}{cccccccccc}
C_{\mathrm{f}} & -a C_{\mathrm{f}} & 0 & 0 & 0 & 0 & 0 & 0 & 0 & 0 \\
C_{\mathrm{r}} & b C_{\mathrm{r}} & 0 & 0 & 0 & 0 & 0 & 0 & 0 & 0
\end{array}\right]^{\mathrm{T}} .
$$

From Eqs. (21) and (22), it can be seen that both $\mathbf{C}_{\boldsymbol{q}}$ and $\mathbf{C}_{\boldsymbol{u}}$ contain $C_{\mathrm{f}}$ and $C_{\mathrm{r}}$. From Eqs. (2) and (3), it can be seen that $C_{\mathrm{f}}$ and $C_{\mathrm{r}}$ are non-linear. Thus, there are non-linear terms in $\mathbf{C}_{\boldsymbol{u}}$ and $\mathbf{C}_{\boldsymbol{q}}$.

Therefore, matrix Eq. (20) is a set of non-linear dynamic equations.

\section{VIBRATION SIGNALS ACQUISITION}

To obtain the vibration signals for simulation and validation, according to the national standard $\mathrm{GB} / \mathrm{T}$ 4970-2009 (China) [22], the road test was carried out, and the vibration signals were collected. The test was conducted on an automobile comprehensive test field. An asphalt road and a gravel road were selected as the test roads. For each road, the pavement is straight, and the longitudinal slope is not more than $1 \%$. A medium-sized truck was selected as the test vehicle. The driver is a male, and his weight is $72.0 \mathrm{~kg}$.

The test equipment is LMS Test.Lab test system, as shown in Fig. 3. Before the test, one accelerometer was installed on the seat surface and one accelerometer was installed on the seat backrest. In addition, two accelerometers were installed on the frame at the mounting positions of the front spring-damper assembly and the rear spring-damper assembly. The four accelerometers are PCB 356A26 accelerometers. During the test, the driver fastened his seat belt and put his hands on the steering wheel and remained still. Moreover, the running speed was $60 \mathrm{~km} / \mathrm{h}$. The sample frequency was set as $512 \mathrm{~Hz}$. The total duration of the collected signal is $120 \mathrm{~s}$ for each measurement. The measured vibration signals on the asphalt road are shown in Fig. 4. The measured vibration signals on the gravel road are similar to those on the asphalt road.

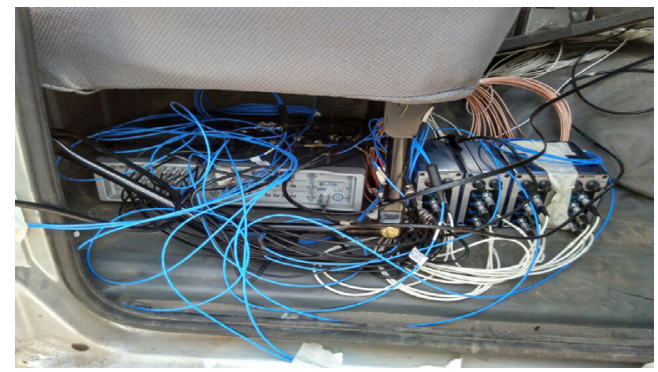

Fig. 3. The LMS Test.Lab system for the test of the vibration signals acquisition 


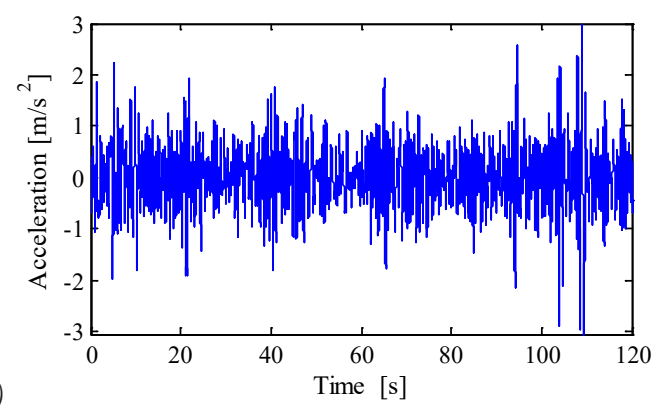

a)
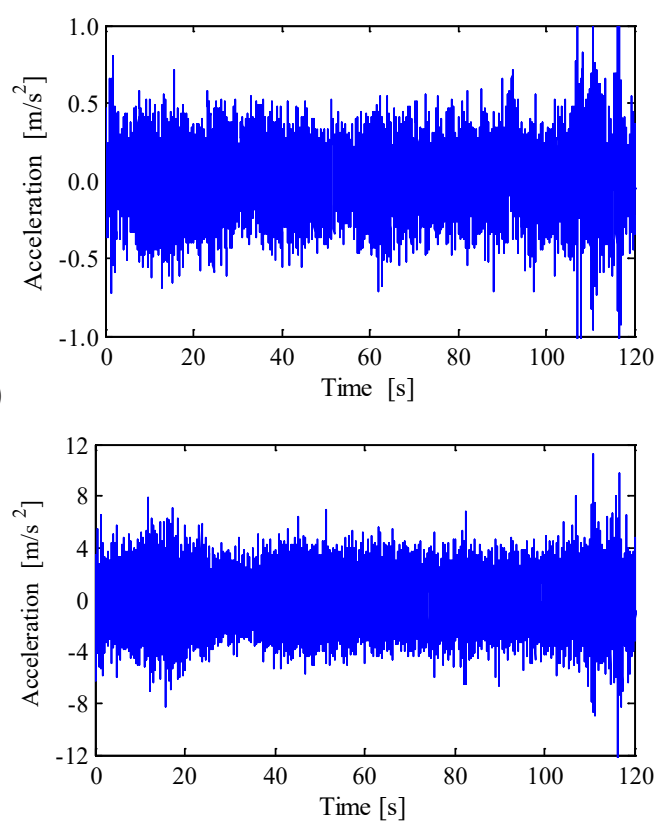

c)

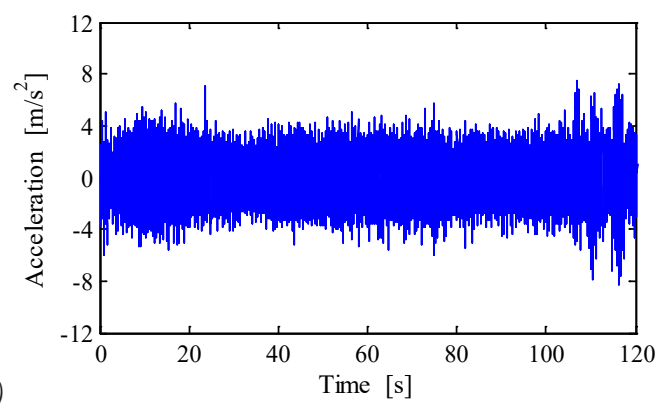

Fig. 4. The measured acceleration signals on the asphalt road: a) the seat surface vertical acceleration, b) the seat backrest longitudinal acceleration, c) the vertical frame acceleration at the mounting position of the front spring-damper assembly, and d) the vertical frame acceleration at the mounting position of the rear spring-damper assembly

\section{NUMERICAL SOLUTION METHOD OF THE NON-LINEAR EQUATION SET}

The solution of Eq. (20) is the solving problem of the non-linear differential equation set. The Newmark- $\beta$ method has good stability and high accuracy [23]. It can easily fulfil the needs of solving complex nonlinear dynamic differential equation set in a large number of projects. Therefore, this method is used to solve the numerical solution of Eq. (20). The iterative equations used in the Newmark- $\beta$ method are as follows:

$$
\begin{gathered}
\dot{\mathbf{u}}_{t+\Delta t}=\dot{\mathbf{u}}_{t}+\left[(1-\beta) \ddot{\mathbf{u}}_{t}+\beta \ddot{\mathbf{u}}_{t+\Delta t}\right] \Delta t, \\
\mathbf{u}_{t+\Delta t}=\mathbf{u}_{t}+\dot{\mathbf{u}}_{t} \Delta t+\left[\left(\frac{1}{2}-\alpha\right) \ddot{\mathbf{u}}_{t}+\alpha \ddot{\mathbf{u}}_{t+\Delta t}\right](\Delta t)^{2} .
\end{gathered}
$$

where, $\mathbf{u}_{t}$ is the displacement vector at time $t, \dot{\mathbf{u}}_{t}$ and $\ddot{\mathbf{u}}_{t}$ are the velocity vector and the acceleration vector at time $t$, respectively; $\mathbf{u}_{t+\Delta t}, \dot{\mathbf{u}}_{t+\Delta t}$, and $\ddot{\mathbf{u}}_{t+\Delta t}$ are the vectors of the displacement, the velocity, and the acceleration at time $t+\Delta t$, respectively. $\alpha$ and $\beta$ are constant.

Based on the Newmark- $\beta$ method, combined with the Eq. (20) and its non-linear characteristics, the specific solution process was given to solve Eq. (20) for the time length $[0, T]$. $T$ is divided into $N$ parts $(n \Delta t=T)$, meaning the integral step is $\Delta t$. In this study, $\Delta t$ was set as the reciprocal of the sampling frequency $512 \mathrm{~Hz}$. The solution process based on Newmark- $\beta$ method is shown in Fig. 5.

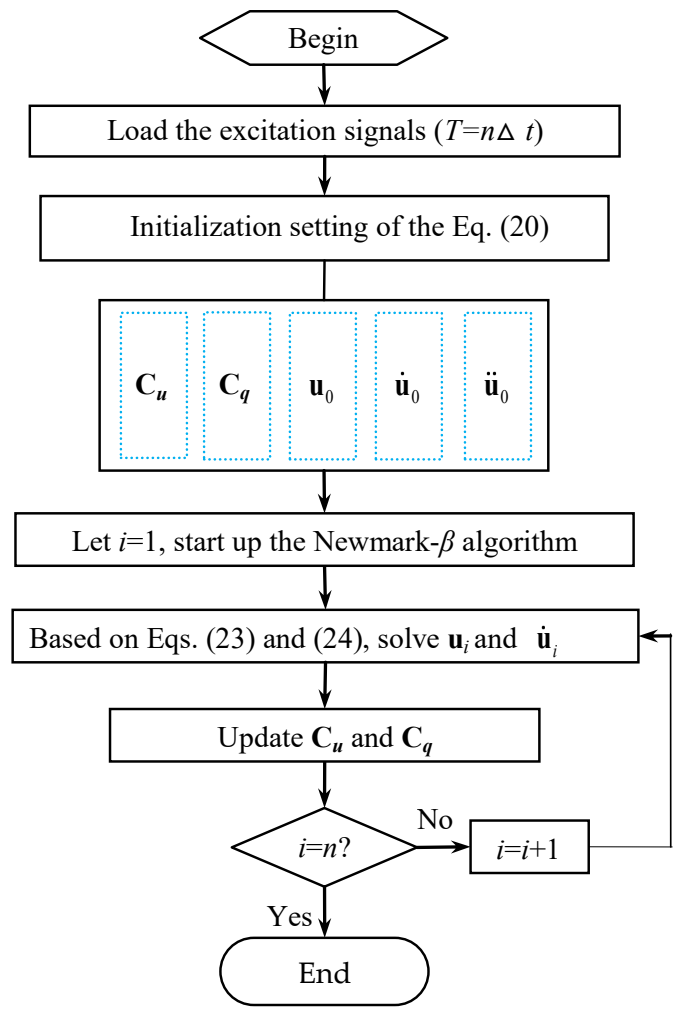

Fig. 5. The specific solution process for the equation set of the proposed model 


\section{MODEL VALIDATION}

In order to verify the effectiveness of the proposed model and equations for the driver-seat cab system, the numerical simulations and comparison of the driver's vibration responses were carried out according to the specific solution process.

\subsection{Model Parameters}

To obtain the damping coefficients of the dampers for the front suspension and the rear suspension of the cab, using the ZJS-30 hydraulic test bench produced by Changchun Test Machine Research Institute, the damping characteristic tests of the dampers were carried out by bench test, as shown in Fig. 6a. The master computer is shown in Fig. 6 b.
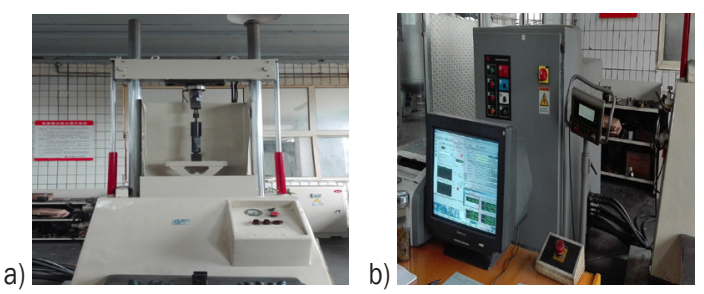

Fig. 6. Damper test; a) the test bench, and b) the master computer

Using the bench test, a sine wave excitation with an amplitude of $30 \mathrm{~mm}$ and a frequency of $1.0 \mathrm{~Hz}$ was exerted on each damper. At the same time, the damper damping force was measured by an NS-WL1 tensioncompression sensor. The damper displacement was measured with a SDVG20 displacement sensor. Based on the measurement data, the master computer automatically calculated the damping coefficients of the tested dampers, as shown in Table 1. Other parameters of the seat-cab system provided by the manufacturer, as shown in Table 2.

Table 1. The values of the damping coefficients

\begin{tabular}{lcc}
\hline Moving stroke & $\begin{array}{c}\text { Front } \\
\text { damper }\end{array}$ & $\begin{array}{c}\text { Rear } \\
\text { damper }\end{array}$ \\
\hline Compression damping coefficient $[\mathrm{Ns} / \mathrm{m}]$ & 2317 & 1574 \\
\hline Rebound damping coefficient $[\mathrm{Ns} / \mathrm{m}]$ & 6256 & 4013 \\
\hline
\end{tabular}

Table 2. The parameters values of the seat-cab system

\begin{tabular}{|c|c|c|c|}
\hline Parameter & Value & Parameter & Value \\
\hline$a[\mathrm{~m}]$ & 0.87 & $I\left[\mathrm{~kg} \cdot \mathrm{m}^{2}\right]$ & 751 \\
\hline$b[\mathrm{~m}]$ & 1.00 & $C_{\mathrm{s}}[\mathrm{Ns} / \mathrm{m}]$ & 592 \\
\hline$h[\mathrm{~m}]$ & 0.25 & $K_{\mathrm{s}}[\mathrm{N} / \mathrm{m}]$ & 15000 \\
\hline$l_{x}[\mathrm{~m}]$ & 0.03 & $K_{\mathrm{f}}[\mathrm{N} / \mathrm{m}]$ & 52000 \\
\hline$m_{\mathrm{c}}[\mathrm{kg}]$ & 810 & $K_{\mathrm{r}}[\mathrm{N} / \mathrm{m}]$ & 32000 \\
\hline
\end{tabular}

According to the curve fitting method in reference [21], by minimizing the errors of the seat-to-head transmissibility function between the computed values using the model and the tested values, the parameters of the human biomechanics model were re-estimated. The previous model parameter values in reference [21] were selected as the initial values in this research. When the root mean square errors converged to 0.01 , the parameter values were determined, as shown in Table 3.

Table 3. The parameters values of the driver model

\begin{tabular}{|c|c|c|c|}
\hline Parameter & Value & Parameter & Value \\
\hline$C_{1}[\mathrm{Ns} / \mathrm{m}]$ & 2375.4 & $K_{1}[\mathrm{~N} / \mathrm{m}]$ & 120103.1 \\
\hline$C_{2}[\mathrm{Ns} / \mathrm{m}]$ & 676.8 & $K_{2}[\mathrm{~N} / \mathrm{m}]$ & 5301.9 \\
\hline$C_{3}[\mathrm{Ns} / \mathrm{m}]$ & 144.8 & $K_{3}[\mathrm{~N} / \mathrm{m}]$ & 13172.5 \\
\hline$C_{4}[\mathrm{Ns} / \mathrm{m}]$ & 1791.7 & $K_{4}[\mathrm{~N} / \mathrm{m}]$ & 9150.8 \\
\hline$C_{41}[\mathrm{Ns} / \mathrm{m}]$ & 4020.2 & $K_{41}[\mathrm{~N} / \mathrm{m}]$ & 128193.0 \\
\hline$C_{5}[\mathrm{Ns} / \mathrm{m}]$ & 979.4 & $K_{5}[\mathrm{~N} / \mathrm{m}]$ & 292014.6 \\
\hline$C_{\mathrm{b}}[\mathrm{Ns} / \mathrm{m}]$ & 621.2 & $K_{\mathrm{b}}[\mathrm{N} / \mathrm{m}]$ & 9925.3 \\
\hline$c_{t}[\mathrm{Ns} / \mathrm{m}]$ & 18.3 & $k_{t}[\mathrm{~N} / \mathrm{m}]$ & 779.0 \\
\hline$m_{1}[\mathrm{~kg}]$ & 10.2 & $m_{4}[\mathrm{~kg}]$ & 20.2 \\
\hline$m_{2}[\mathrm{~kg}]$ & 9.0 & $m_{5}[\mathrm{~kg}]$ & 5.8 \\
\hline$m_{3}[\mathrm{~kg}]$ & 8.1 & $l_{\mathrm{n}}[\mathrm{m}]$ & 0.19 \\
\hline
\end{tabular}

\subsection{The Effectiveness Validation of the Proposed Model}

In this section, the simulations were conducted and the simulation results were verified with the tested results. For the simulations, the measured frame vertical acceleration signals at the mounting positions of the front spring-damper assembly and the rear spring-damper assembly were taken as the inputs. The simulation time $T$ was set as $120 \mathrm{~s}$. The lower torso vertical frequency-weighted RMS (root mean square) acceleration values were calculated from the simulated $\ddot{z}_{1}$ and the measured $\ddot{z}_{1}$, respectively. The driver body longitudinal frequency-weighted RMS acceleration values were calculated from the simulated $\ddot{x}_{\mathrm{b}}$ and the measured $\ddot{x}_{\mathrm{b}}$, respectively. A comparison of the frequency-weighted RMS acceleration values calculated from the measured data and from the simulated data is shown in Table 4.

From Table 4, it can be seen that the relative errors of the driver body longitudinal frequencyweighted RMS acceleration values calculated from the simulated $\ddot{x}_{\mathrm{b}}$ and the measured $\ddot{x}_{\mathrm{b}}$ are less than 20 $\%$; the relative errors of the lower torso vertical frequency-weighted RMS acceleration values calculated from the simulated $\ddot{z}_{1}$ and the measured $\ddot{z}_{1}$ are less than $10 \%$. In the longitudinal direction ( $x$-direction), the relative errors are larger than those 
in the vertical direction. Moreover, the driver body longitudinal frequency-weighted RMS acceleration values calculated from the simulated $\ddot{x}_{\mathrm{b}}$ are less than those calculated from the measured $\ddot{x}_{\mathrm{b}}$. The main reasons are as follows: firstly, in the modelling process, the cab longitudinal acceleration $\ddot{x}_{\mathrm{c}}$ was not considered. According to Eq. (14), the longitudinal acceleration $\ddot{x}_{\mathrm{cs}}$ of the seat backrest can be expressed as $\ddot{x}_{\mathrm{cs}}=-h \ddot{\varphi}$. In fact, $\ddot{x}_{\mathrm{cs}}$ should be written as $\ddot{x}_{\mathrm{cs}}=-h \ddot{\varphi}+\ddot{x}_{\mathrm{c}}$. Secondly, there are some errors in the 7 DOF driver biodynamic model. From the previous work [21], the model shows a higher average goodness-of-fit in the vertical direction than in the fore-and-aft direction. Moreover, in the fore-and-aft direction, the average goodness-of-fit is slightly larger than $80 \%$. It is noted that, although the driver model accuracy is not ideal, the fitting results show an improved fit compared with other existing human models.

Table 4. A comparison of the frequency-weighted RMS acceleration values

\begin{tabular}{cccccc}
\hline Road & Response & $\begin{array}{c}\text { Measured } \\
{\left[\mathrm{m} / \mathrm{s}^{2}\right]}\end{array}$ & $\begin{array}{c}\text { Simulated } \\
{\left[\mathrm{m} / \mathrm{s}^{2}\right]}\end{array}$ & $\left.\begin{array}{c}\text { Absolute } \\
\text { error [m/s }\end{array} \mathrm{s}^{2}\right]$ & $\begin{array}{c}\text { Relative } \\
\text { error [\%] }\end{array}$ \\
\hline \multirow{2}{*}{$\begin{array}{c}\text { Asphalt } \\
\text { road }\end{array}$} & $\ddot{z}_{1}$ & 0.34 & 0.37 & 0.03 & 8.8 \\
\cline { 2 - 6 } & $\ddot{x}_{\mathrm{b}}$ & 0.16 & 0.13 & 0.03 & 18.7 \\
\hline $\begin{array}{c}\text { Gravel } \\
\text { road }\end{array}$ & $\ddot{z}_{1}$ & 0.56 & 0.51 & 0.05 & 8.9 \\
\cline { 2 - 6 } & $\ddot{x}_{\mathrm{b}}$ & 0.26 & 0.21 & 0.05 & 19.2 \\
\hline
\end{tabular}

By comparison, the results show that the simulation values agree with the test values. Although the proposed model should be further improved, the model is workable, and the model accuracy is acceptable. The proposed model can effectively predict the driver's biomechanical responses and basic dynamic characteristics for trucks running on random roads.

\section{BIOMECHANICAL SIMULATION OF DRIVER COUPLED WITH SEAT-CAB}

\subsection{Simulation Analysis of the Time Domain Responses}

In the prediction and analysis of ride comfort, it is helpful to understand the changes of the human vibration in time series. The time-domain analysis of the driver's biomechanical responses is conducive to the design and the control of vehicle suspension systems. Moreover, it can help designers to determine the problems in design and to make corresponding improvements.
The simulations were conducted using the proposed model to investigate the driver's biomechanical responses for trucks running on random roads, taking the collected frame vibration signals as the inputs. The simulated force and acceleration responses for trucks running on the asphalt road are shown in Fig. 7. The simulated driver's biomechanical responses for trucks running on the gravel road are similar to those on the asphalt road. The RMS force values and the frequency-weighted RMS acceleration values of the driver's different parts and different directions are shown in Table 5 and Table 6 , respectively.

Table 5. The RMS force values

\begin{tabular}{lcc}
\hline Position & $\begin{array}{c}\text { Asphalt } \\
\text { road }\end{array}$ & $\begin{array}{c}\text { Gravel } \\
\text { road }\end{array}$ \\
\hline The head for the vertical motion [N] & 3.79 & 4.55 \\
\hline The upper torso for the vertical motion [N] & 13.71 & 17.82 \\
\hline The arms for the vertical motion [N] & 5.87 & 7.04 \\
\hline The viscera for vertical motion [N] & 6.25 & 7.50 \\
\hline The lower torso for the vertical motion [N] & 6.56 & 8.20 \\
\hline The whole-body for longitudinal motion [N] & 6.15 & 7.38 \\
\hline The head for the pitch motion [Nm] & 0.10 & 0.13 \\
\hline
\end{tabular}

Table 6. The frequency-weighted RMS acceleration values

\begin{tabular}{lcc}
\hline Position & $\begin{array}{c}\text { Asphalt } \\
\text { Road }\end{array}$ & $\begin{array}{c}\text { Gravel } \\
\text { road }\end{array}$ \\
\hline The head for the vertical motion $\left[\mathrm{m} / \mathrm{s}^{2}\right]$ & 0.37 & 0.53 \\
\hline The upper torso for the vertical motion $\left[\mathrm{m} / \mathrm{s}^{2}\right]$ & 0.37 & 0.52 \\
\hline The arms for the vertical motion $\left[\mathrm{m} / \mathrm{s}^{2}\right]$ & 0.43 & 0.57 \\
\hline The viscera for vertical motion $\left[\mathrm{m} / \mathrm{s}^{2}\right]$ & 0.37 & 0.53 \\
\hline The lower torso for the vertical motion $\left[\mathrm{m} / \mathrm{s}^{2}\right]$ & 0.36 & 0.51 \\
\hline The whole-body for longitudinal motion $\left[\mathrm{m} / \mathrm{s}^{2}\right]$ & 0.13 & 0.24 \\
\hline The head for the pitch motion $\left[\mathrm{rad} / \mathrm{s}^{2}\right]$ & 0.24 & 0.32 \\
\hline
\end{tabular}

From Fig. 7, it can be seen that the time histories of the forces of the lower torso, the viscera, the arms, the upper torso, and the head are very similar. Table 5 shows that the RMS force values of the upper torso are larger than those of other organs. For trucks running on the asphalt road, the RMS force value of the upper torso is nearly twice as large as that of the lower torso. The RMS force values illustrate a similar rule for trucks running on the gravel road. Table 6 shows that the frequency-weighted RMS acceleration values of the viscera, the arms, the upper torso, and the head are all larger than that of the lower torso. For trucks running on the asphalt road, the frequencyweighted RMS acceleration value of the arms is $19.4 \%$ larger than that of the lower torso. For trucks running on the gravel road, the frequency-weighted 


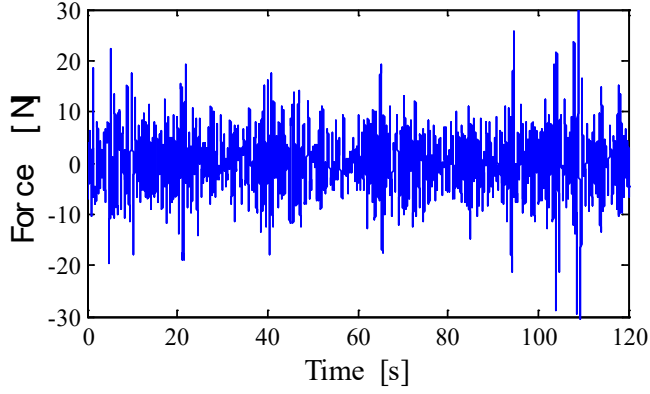

a)

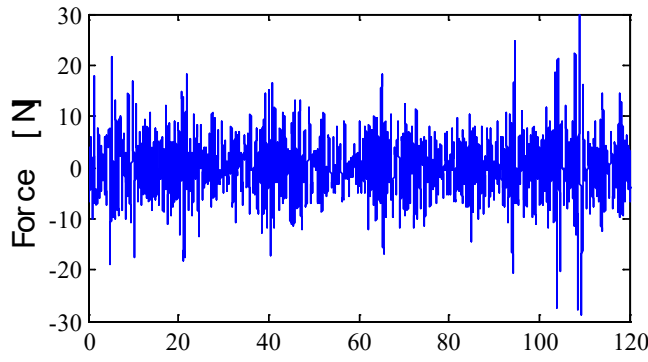

b)
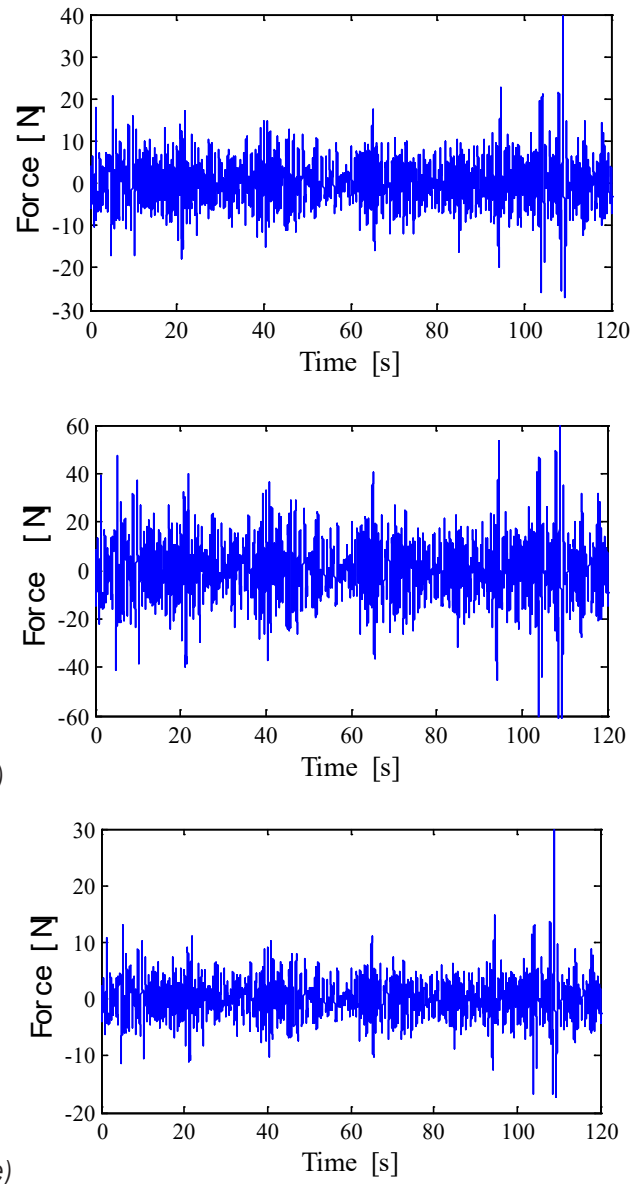
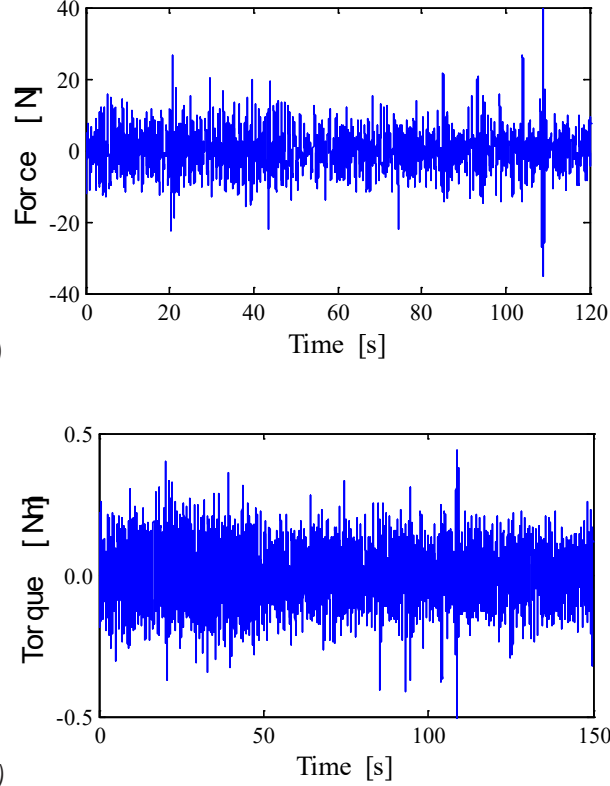

g)
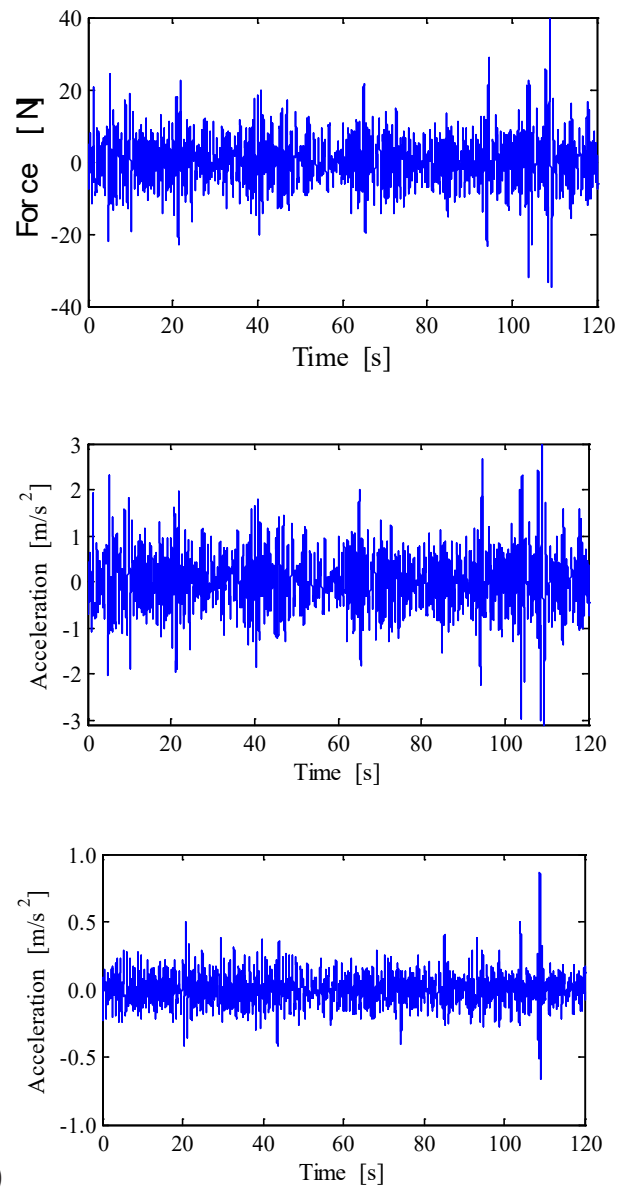

Fig. 7. The simulated vibration responses for trucks running on the asphalt road: a) the lower torso vertical force, $b$ ) the viscera vertical force, c) the arms vertical force, d) the upper torso vertical force, e) the head vertical force, f) the whole-body longitudinal force, g) the head pitch torque, $h$ ) the seat vertical force, i) the upper torso vertical acceleration, and j) the whole-body longitudinal acceleration 
RMS acceleration values illustrate the similar rule. The results show that the driver body can amplify the vertical vibration of the lower torso for trucks running on the asphalt road and the gravel road.

\subsection{Simulation Analysis of the Frequency Domain Responses}

To analyse the relationship between the vibration energy and the vibration frequency of each part of the driver body, based on the simulated force responses in the time domain, the PSD (power spectral density) curves were plotted, as shown in Fig. 8.

From Fig. 8, it can be seen that when the truck drives on the asphalt road, the driver's body vertical vibration energy caused by the road excitation mainly concentrates in the low-frequency section $(0.5 \mathrm{~Hz}$ to $10.0 \mathrm{~Hz}$ ). The driver's body vibration energy in the high-frequency segment $(10.0 \mathrm{~Hz}$ to $100.0 \mathrm{~Hz})$ is almost zero. The frequency section of the most extreme concentration for the vibration energy is about from $1.0 \mathrm{~Hz}$ to $5.0 \mathrm{~Hz}$. The largest resonance peak appears at about $1.5 \mathrm{~Hz}$. This is related to the natural frequencies of the cab system. From the vibration in Eq. (20), it can be obtained that the vertical vibration natural frequency is $1.35 \mathrm{~Hz}$ and the pitch vibration natural frequency is $1.70 \mathrm{~Hz}$ for the cab system. Figs. 8 a to e show that the PSD curves of the vertical forces of the lower torso, the viscera, the arms, the upper torso, and the head are very similar. Fig. $8 \mathrm{f}$ illustrates that the longitudinal vibration energy of the driver's body concentrates in the low-frequency section from $1.0 \mathrm{~Hz}$ to $8.0 \mathrm{~Hz}$. These simulation results are consistent with the results of the human vibration characteristics test [24] and [25].

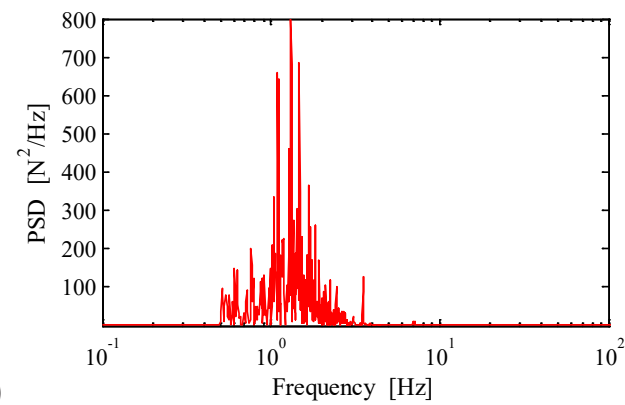

d)

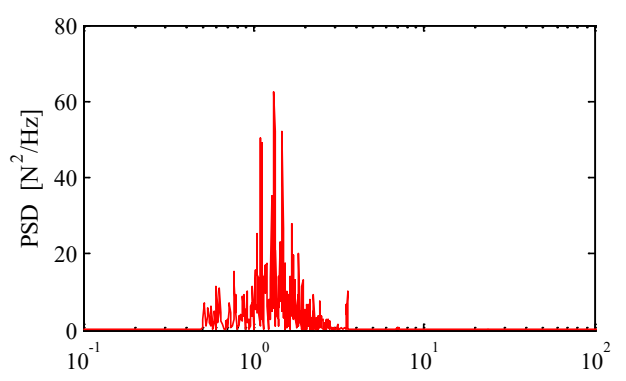

e)

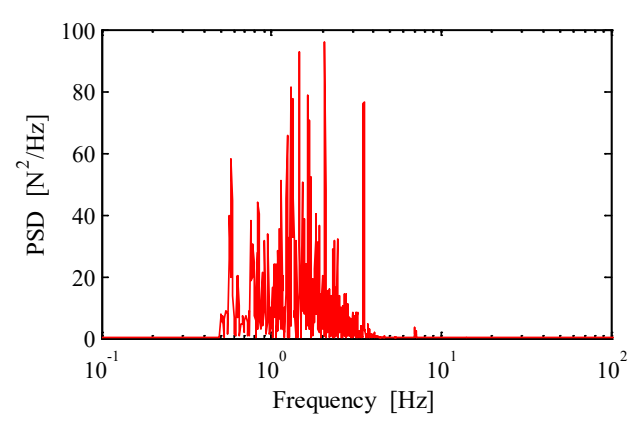

c)

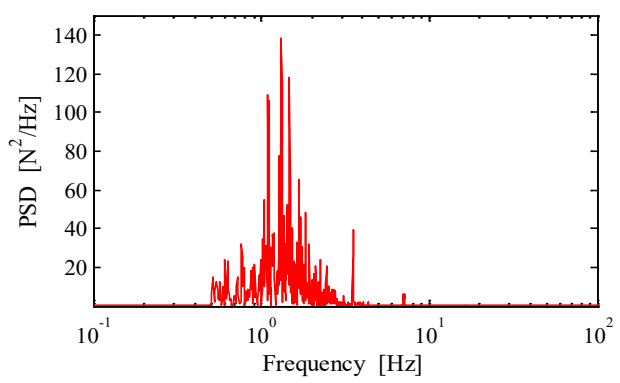

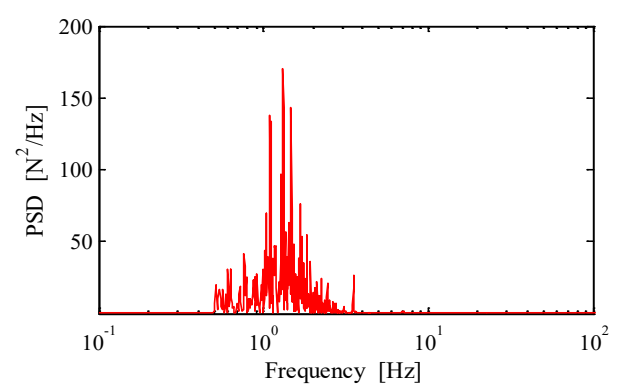

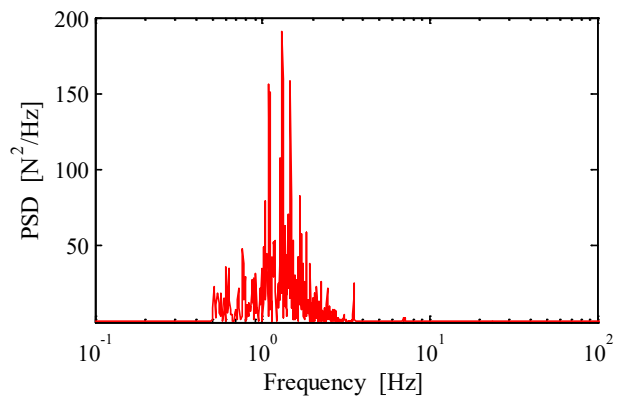

Fig. 8. The PSD curves for trucks running on the asphalt road: a) lower torso vertical force, b) viscera vertical force, c) arms vertical force, d) upper torso vertical force, e) head vertical force; f) whole-body longitudinal force 


\section{CONCLUSIONS}

This paper aims to provide a reliable model and method for effectively predicting the responses characteristics of the driver-seat-cab system. Based on the 7 DOF seated human biodynamic model established previously, a 10 DOF non-linear dynamic model of the driver-seat-cab system was created, and its vibration differential equations were established. The vibration signals for simulation and verification were collected through the road test. Based on the Newmark- $\beta$ integration method, the specific solution process of the model was given. The non-linear damping coefficients of the front and rear dampers for the cab suspensions were measured with a bench test. The proposed model was validated, and the simulations were numerically conducted. Some useful conclusions were drawn:

(1) By comparison, the results show that the simulation values agree with the test values. The model is workable, and the model accuracy is acceptable. The proposed model can effectively predict the driver's biomechanical responses and basic dynamic characteristics for trucks undergoing random roads excitation.

(2) The time histories of the vertical forces and accelerations of the lower torso, the viscera, the arms, the upper torso, and the head are similar for trucks undergoing random roads excitation.

(3) When the truck runs on the asphalt road, the driver's body vertical vibration energy caused by the road excitation mainly concentrates in the low-frequency section $(0 \mathrm{~Hz}$ to $10.0 \mathrm{~Hz})$. The driver's body vibration energy in the highfrequency segment $(10.0 \mathrm{~Hz}$ to $100.0 \mathrm{~Hz})$ is almost zero.

To reasonably evaluate the design effect of the cab suspension system, it is necessary to assess the cab comfort objectively. According to the ISO 2631-1 standard [14], the cab comfort is usually evaluated on the basis of the vibration accelerations at the driver's backrest and hip. However, the existing cab model can only simulate the vibration of the cab floor. Therefore, based on the existing cab model, the cab comfort cannot be accurately and comprehensively simulated. The proposed model in this paper can overcome the shortcomings of the existing model, and can more effectively simulate the vibration accelerations at the driver's backrest and hip. It can be seen that the proposed model is more helpful to guide the matching and designing of the cab suspension system than the existing model. In addition, the proposed model can also be used to analyse the driver's whole- body vibration when the truck is impacted, which can provide a theoretical basis for taking effective measures to avoid the injury of the driver's viscera. It should be noted that the model is not suitable for the vibration fatigue analysis of the human body. The shortcoming of the proposed model is that it can not accurately reproduce the real longitudinal acceleration. Thus, to overcome the shortcoming, the longitudinal DOF of the cab should be considered, and the guide mechanism of the cab suspension system should be built into the dynamic model in the following study.

\section{ACKNOWLEDGEMENTS}

This work is supported by Nature Science Foundation of Shandong (ZR2020ME127) and the National Natural Science Foundation of China (11802338).

\section{REFERENCES}

[1] Basaran, S., Basaran, M. (2020). Vibration control of truck cabins with the adaptive vectorial backstepping design of electromagnetic active suspension system. IEEE Access, vol. 8, p. 173056-173067, DOI:10.1109/ACCESS.2020.3025357.

[2] Nataraj, M., Thillikkani, S. (2020). Failure analysis of leaf spring suspension system for heavy load truck vehicle. International Journal of Heavy Vehicle Systems, vol. 27, no. 1-2, p. 1-17, D0I:10.1504/IJHVS.2020.104413.

[3] Wang, G., Li, K., Yang, J., Liang, C. (2017). Simulation and vibration isolation optimization on the cab mount of a commercial vehicle. Automotive Engineering, vol. 39, no. 9, p. 1081-1086.

[4] Zhao, L.L., Yu, Y.W., Zhou, C.C., Li, X.H. (2018). Throttle slice opening size and damping characteristics of cab damper for special vehicles. Acta Armamentarii, vol. 39, no. 4, p. 645654.

[5] Nguyen, V., Jiao, R., Zhang, J. (2020). Control performance of damping and air spring of heavy truck air suspension system with optimal fuzzy control. SAE International Journal of Vehicle Dynamics, Stability, and NVH, vol. 4, no. 2, p. 179-194, DOl:10.4271/10-04-02-0013.

[6] Diba, F., Esmailzadeh, E. (2018). Development of hybrid electric heavy-duty truck with self-propelled trailer. International Journal of Heavy Vehicle Systems, vol. 25, no. 2, p. 203-222, DOI:10.1504/IJHVS.2018.10011869.

[7] Lee, D.Y., Elgowainy, A., Kotz, A., Vijayagopal, R., Marcinkoski, J. (2018). Life-cycle implications of hydrogen fuel cell electric vehicle technology for medium- and heavy-duty trucks. Journal of Power Sources, vol. 393, p. 217-229, D0l:10.1016/j. jpowsour.2018.05.012.

[8] Yang, F.X., Zhao, L.L., Yu, Y.W., Zhou, C.C. (2017). Analytical description of ride comfort and optimal damping of cushionsuspension for wheel-drive electric vehicles. International Journal of Automotive Technology, vol. 18, no. 6, p. 11211129, D0I:10.1007/s12239-017-0109-2. 
[9] Nazemian, H., Masih-Tehrani, M. (2020). Hybrid fuzzy-PID control development for a truck air suspension system. SAE International Journal of Commercial Vehicles, vol. 13, no. 1, p. 55-69, D0I:10.4271/02-13-01-0004.

[10] Zhao, L.L., Yu, Y.W., Zhou, C.C., Li; X.H., Huang, D.H. (2020). Analytical simulation of dynamic characteristics of seat system with non-linear suspension considering friction effects. International Journal of Modeling, Simulation, and Scientific Computing, vol. 11, no. 6, p. art. ID 2050058, D0l:10.1142/ \$1793962320500580.

[11] Rossa, F.D., Mastinu, G. (2017) Analysis of the lateral dynamics of a vehicle and driver model running straight ahead. Nonlinear Dynamics, vol. 92, p. 97-106, D0l:10.1007/ s11071-017-3478-1.

[12] Maradei, M.F., Quintana, L., Castellanos-Olarte, J.M. (2016). Assessment of biomechanical demands and discomfort in drivers to stablish design criteria for truck seats. International Journal on Interactive Design and Manufacturing, vol. 10, p. 431-437, D0I:10.1007/s12008-016-0325-4.

[13] Kim, J.H., Marin, L.S., Dennerlein, J.T. (2018). Evaluation of commercially available seat suspensions to reduce whole-body vibration exposures in mining heavy equipment vehicle operators. Applied Ergonomics, vol. 71, p. 78-86, D0I:10.1016/j.apergo.2018.04.003.

[14] ISO 2631-1:1997. Mechanical vibration and shock-evaluation of human exposure to whole-driver vibration-part 1: general requirements. International Organization for Standardization; Geneva.

[15] Stein, G.J. Múčka, P., Gunston, T.P. (2009). A study of locomotive driver's seat vertical suspension system with adjustable damper. Vehicle System Dynamics, vol. 47, no. 3, p. 363-386, DOI:10.1080/00423110802148920.

[16] Marcu, F.M. (2009). Semiactive Cab Suspension Control for Semitruck Applications. Virginia Polytechnic Institute and State University, Blacksburg.

[17] Akcay, H., Türkay, S. (2014) Stochastic optimal control of truck cabin with active suspension. International Journal of Heavy
Vehicle Systems, vol. 21, no. 3, p. 183-207, D0l:10.1504/ IJHVS.2014.066067.

[18] Wang, T., Wang, L., Li, T., Zou, X. (2017). Fatigue failure assessment based on loading reproduction for commercial vehicle cab. Journal of Huazhong University of Science and Techology, vol. 45, no. 5, p. 61-66.

[19] Liu, W., Wang, T., Shen, J., Yi, C. (2017). Ride comfort optimization of cab mounts based on response surface method. Automotive Engineering, vol. 39, no. 3, p. 323-334.

[20] Zhao, L.L., Guo, J., Yu, Y.W., Li, X.H, Zhou; CC. (2020). Simulation of non-linear vibration responses of cab system subject to suspension damper complete failure for trucks. International Journal of Modeling, Simulation, and Scientific Computing, vol. 11, no. 2, p. 2050017-1 2050017-13, DOI:10.1142/S1793962320500178.

[21] Gan, Z., Hillis, A.J., Darling, J. (2015). Biodynamic modelling of seated human subjects exposed to uncouples vertical and fore-and-aft whole-body vibration. Journal of Vibration Engineering and Technologies, vol. 3, no. 3, p. 301-314.

[22] GB / T 4970 (2009). Method of running test-Automotive ride comfort. The Standardization Administration of China, Beijing.

[23] Pourzeynali, S., Zhu, X., Zadeh, A.G., Rashidi, M., Samali, B. (2021). Comprehensive study of moving load identification on bridge structures using the explicit form of newmark- $\beta$ method: Numerical and experimental studies. Remote Sensing, vol. 13, no. 12, art. ID 2291, D0I:10.3390/rs13122291.

[24] Duarte, M.L.M., de Melo, G.C. (2018). Influence of pavement type and speed on whole body vibration (WBV) levels measured on passenger vehicles. Journal of the Brazilian Society of Mechanical Sciences and Engineering, vol. 40, no. 3, D0I:10.1007/s40430-018-1057-0.

[25] Huang, Y., Ferguson, N.S. (2018). Identification of biomechanical nonlinearity in whole-body vibration using a reverse path multi-input-single-output method. Journal of Sound and Vibration, vol. 419, p. 337-351, D0l:10.1016/j. jsv.2018.01.002. 